Original Article

\title{
Intra-rater reliability of measurement of abdominal perimuscular connective tissue thickness on ultrasound images
}

\author{
Wataru NanikaWA, RPT, MSc ${ }^{1,2)^{*}}$, JunYa MiYaZaKi, RPT, PhD ${ }^{3)}$ \\ 1) Department of Physical Therapy, Faculty of Health Science, Aino University: 4-5-4 Higashioda, \\ Ibaraki-shi, Osaka 567-0012, Japan \\ 2) Graduate School of Comprehensive Rehabilitation, Osaka Prefecture University, Japan \\ 3) Department of Physical Therapy, Faculty of Health Science, Kyoto Tachibana University, Japan
}

\begin{abstract}
Purpose] The thickness of the perimuscular connective tissue (PMCT) reflects muscular atrophy and decreased flexibility that may cause low back pain. However, few studies have used ultrasound imaging to measure PMCT thickness. We aimed to examine and confirm the reliability of ultrasound in measuring the thickness of the PMCT of the abdominal wall muscle. [Participants and Methods] The participants were 38 healthy adult males without chronic back pain. The images were acquired in B mode with the participants in the supine position and the PMCT thickness of the abdominal wall muscle was measured on the images. The intraclass correlation coefficient (ICC) was used to confirm reliability. [Results] The ICC for both within-day and between-day PMCT measurements by ultrasound were $0.7-0.9$. The $95 \%$ confidence interval ranged from $0.5-0.9$. The standard error of measurement (SEM) was $0.02-0.1 \mathrm{~mm}$ in the abdominal wall muscle and $0.5 \mathrm{~mm}$ in the interrecti distance (IRD). The $95 \%$ confidence interval $(95 \% \mathrm{CI})$ of the minimum detectable change (MDC95) was $0.1-0.3 \mathrm{~mm}$ in the abdominal wall muscle and 1.3-1.4 $\mathrm{mm}$ in the IRD. [Conclusion] We conducted a study to confirm the reliability of ultrasoundbased measurement of PMCT thickness of the abdominal wall muscle, and the ICC results established reliability. However, since the values measured were small $(0.02-1.4 \mathrm{~mm})$ and there is a limit to visual observation, it was necessary to measure using computer software.

Key words: Ultrasound measurement, Perimuscular connective tissue, Reliability
\end{abstract}

(This article was submitted Aug. 19, 2020, and was accepted Oct. 7, 2020)

\section{INTRODUCTION}

Although many studies have been conducted on chronic low back pain, it is understood that the relationship between the cause and symptoms is difficult to identify. In addition, a large amount of medical expense is paid due to chronic low back pain, and it becomes a great financial burden for patients when work is not possible ${ }^{1}$. Many patients with acute low back pain are expected to improve without specific treatment, but distinguishing the cause of pain in patients with recurrent or chronic low back pain is not clear ${ }^{2}$. Moreover, it is said that $80 \%$ or more of chronic low back pain is non-specific, whose image findings do not match clinical findings ${ }^{3}$. Chronic low back pain has been reported to show excessive activity of the trunk muscles associated with the upper limbs and abnormal reactions of the trunk muscles associated with breathing while resting ${ }^{4-7)}$. Motor control exercise and stabilizing exercise are often selected as treatments for chronic low back pain ${ }^{8,9)}$. The following reports have been made on the motor control exercise. In addition to the minimal intervention in low back pain treatment, it can be expected to be effective by further adding motor control exercise ${ }^{8,9)}$, an effect for a short period of time ${ }^{10)}$, it has been shown to have the effect of reducing pelvic compensation exercises and excessive muscle activity ${ }^{11)}$.

*Corresponding author. Wataru Nanikawa (E-mail: w-nanikawa@pt-u.aino.ac.jp)

(C2021 The Society of Physical Therapy Science. Published by IPEC Inc.

(c) (1) $\odot$ This is an open-access article distributed under the terms of the Creative Commons Attribution Non-Commercial No DerivacC. 
The diaphragm, lumbar multifidus, abdominal wall muscles, and pelvic floor muscles are connected through the perimuscular connective tissue (PMCT) and work in concert to increase intra-abdominal pressure and play an important role in trunk stability ${ }^{12)}$. PMCT is also known to remodel in response to micro stress, which is attributed to compensatory motor control. As a result of increased load, microtrauma, inflammation, and PMCT fibrosis occur. Moreover, the reduction of load is said to cause atrophy, structural disassembly, and adhesion. From these results, it is considered that the thickness of PMCT reflects muscular atrophy and decreased flexibility ${ }^{12,13)}$. In recent years, ultrasound measurement has been attracting attention because it can structurally and functionally evaluate deep muscles such as the lumbar and abdominal wall muscles, while being relatively inexpensive and noninvasive ${ }^{14,15)}$. Research on ultrasound measurement is increasing. One study stated that ultrasound measurements yield results similar to those obtained by measuring with an instrument such as a magnetic resonance imaging (MRI) scanner ${ }^{16)}$, and another study described the importance of multiple measurements through investigating the reliability of ultrasound measurements ${ }^{17-21)}$. However, there are still few studies that have performed ultrasound measurements on PMCT, which is said to play an important role in controlling the lumbar region and trunk, both structurally and functionally ${ }^{12,22)}$.

Therefore, in this study, we aimed to confirm and examine by ultrasound measurement the reliability of PMCT measurement of the abdominal wall muscle.

\section{PARTICIPANTS AND METHODS}

The participants were 38 healthy adult males without chronic back pain. Additionally, the participants had no pain from the lower back to the pelvis within the previous 6 months, no symptoms such as numbness in the lower limbs, and had not been diagnosed with lumbar spondylolysis, spondylolisthesis, or lumbar disc herniation. The participants' age, height, and weight were $21.6 \pm 0.5$ years, $169.8 \pm 5.2 \mathrm{~cm}$, and $63.2 \pm 8.1 \mathrm{~kg}$, respectively. The content of the research and obtained data will not be used for anything other than the research itself. Moreover, informed consent was obtained from all participants. This study was carried out with the approval of the Aino University Research Ethics Committee (Aino2019-09) and Kyoto Tachibana University Research Ethics Committee (19-13).

Using an ultrasound imaging device, Noblus (Hitachi, Ltd., Tokyo, Japan), the PMCT thickness of the abdominal wall muscle was measured in a supine position in B mode with a linear L64 probe (5-18 MHz). The measured position was a supine position placed on the body side with both upper limbs relaxed, and the measurement was performed during the final exhalation, at rest. The record value was an average value measured twice to reduce error. Regarding the measurement method, PMCT was measured with reference to the method of Whittaker et $\mathrm{al}^{12}$. In the PMCT, the shallow layer of the external oblique muscle was PMCT-external oblique (PMCT-EO). The layer between the external oblique muscle and the internal oblique muscle was PMCT-external oblique to internal oblique (PMCT-EO to IO). The layer between the internal oblique muscle and the transverse abdominal muscle was PMCT-internal oblique to transversus abdominis (PMCT-IO to TrA). The deep layer of the transverse abdominal muscle was PMCT-transversus abdominis (PMCT-TrA). The shallow layer of the rectus abdominis was PMCT-anterior rectus abdominis (PMCT-ARA). The deep layer of the rectus abdominis was PMCT-posterior rectus abdominis (PMCT-PRA). The linea alba was the interrecti distance (IRD). The thickness of PMCT was measured on the mid-axillary line between the right iliac crest and the lower ribs. The thickness of the rectus abdominis PMCT was measured at the height of the navel level in the center of the right rectus abdominis. For the thickness of PMCT, the distance from the fascia outer edge to the fascia inner edge was measured. The IRD, which is the distance between the rectus muscles, was measured in the center of the abdomen below the umbilicus. The IRD thickness was measured between the inner edge of two rectus abdominis muscles. Anterior abdominal wall connective tissue (AAWCT) was calculated by the sum of PMCT-ARA and PMCT-PRA. Lateral abdominal wall connective tissue (LAWCT) was calculated as the sum of PMCT-EO to IO, PMCT-IO to TrA and PMCT-TrA ${ }^{12)}$. Each measurement area was marked with an oil marker so that the measurement area could be reproduced. The pressure applied by the probe was set to the minimum strength at which each muscle was clearly visible on the screen. At that time, the position and gain of the probe were finely adjusted so that the boundary of each muscle was exposed. The measurement frequency that enabled each muscle and PMCT to be clearly visible ranged from 5-18 MHz. To keep the pressure during measurement constant, the measurer was one physical therapist accustomed to ultrasound measurement, and the measurement was performed after sufficient practice.

These were verified for reliability. To confirm whether there was an influence of the within-day intra-rater reliability, the results measured twice within the same day were examined by intraclass correlation coefficient (ICC). In addition, to confirm whether there was an influence of the between-day intra-rater reliability, the results of remeasurement within 2 weeks were examined with the results of the first measurement and ICC. ICC interpretation is based on Cicchetti and Sparrow ${ }^{23)}: 0.40$ or less is low reliability, $0.40-0.59$ is medium reliability, $0.60-0.75$ is good reliability, and 0.75 or more indicates excellent reliability. SPSS version 20 for Windows (IBM Co., Armonk, NY, USA) was used for the ICC statistical analysis. In addition, the measurement error was calculated using the $95 \%$ confidence interval $(95 \% \mathrm{CI})$ of the minimum detectable change $\left(\mathrm{MDC}_{95}\right)$. $\mathrm{MDC}_{95}$ was determined by $\mathrm{MDC}_{95}=$ standard error of measurement $\left.(\mathrm{SEM}) \times 1.96 \times \sqrt{ } 2^{24}\right)$. 
Table 1. Within-day and between-day intrarater reliability measurements (38 males)

\begin{tabular}{|c|c|c|c|c|c|c|c|c|c|c|c|c|}
\hline & & & \multicolumn{5}{|c|}{ Right } & \multicolumn{5}{|c|}{ Left } \\
\hline & & & $\begin{array}{l}\text { Mean } \\
(\mathrm{mm})\end{array}$ & ICC & $95 \% \mathrm{CI}$ & $\begin{array}{l}\text { SEM } \\
(\mathrm{mm}) \\
\end{array}$ & $\begin{array}{c}\mathrm{MDC}_{95} \\
(\mathrm{~mm})\end{array}$ & $\begin{array}{l}\text { Mean } \\
(\mathrm{mm})\end{array}$ & ICC & $95 \% \mathrm{CI}$ & $\begin{array}{l}\text { SEM } \\
(\mathrm{mm})\end{array}$ & $\begin{array}{c}\mathrm{MDC}_{95} \\
(\mathrm{~mm})\end{array}$ \\
\hline \multirow{14}{*}{ Within } & \multirow[t]{2}{*}{ PMCT-EO } & $1 \mathrm{st}$ & $1.4 \pm 0.4$ & \multirow{2}{*}{0.94} & \multirow{2}{*}{$0.89-0.97$} & 0.1 & 0.2 & $1.3 \pm 0.4$ & \multirow{2}{*}{0.94} & \multirow{2}{*}{$0.89-0.97$} & 0.1 & 0.2 \\
\hline & & 2 nd & $1.4 \pm 0.4$ & & & 0.1 & 0.3 & $1.3 \pm 0.4$ & & & 0.1 & 0.2 \\
\hline & \multirow[t]{2}{*}{ PMCT-EO to IO } & $1 \mathrm{st}$ & $0.9 \pm 0.2$ & \multirow{2}{*}{0.89} & \multirow{2}{*}{$0.80-0.94$} & 0.03 & 0.1 & $1.0 \pm 0.2$ & \multirow{2}{*}{0.90} & \multirow{2}{*}{$0.81-0.95$} & 0.04 & 0.1 \\
\hline & & 2 nd & $1.0 \pm 0.2$ & & & 0.03 & 0.1 & $0.9 \pm 0.2$ & & & 0.04 & 0.1 \\
\hline & \multirow[t]{2}{*}{ PMCT-IO to TrA } & $1 \mathrm{st}$ & $1.1 \pm 0.2$ & \multirow{2}{*}{0.88} & \multirow{2}{*}{$0.78-0.94$} & 0.03 & 0.1 & $1.1 \pm 0.2$ & \multirow{2}{*}{0.81} & \multirow{2}{*}{$0.67-0.90$} & 0.03 & 0.1 \\
\hline & & 2 nd & $1.1 \pm 0.2$ & & & 0.03 & 0.1 & $1.1 \pm 0.2$ & & & 0.03 & 0.1 \\
\hline & \multirow[t]{2}{*}{ PMCT-TrA } & $1 \mathrm{st}$ & $1.0 \pm 0.2$ & \multirow{2}{*}{0.78} & \multirow{2}{*}{$0.62-0.88$} & 0.03 & 0.1 & $1.0 \pm 0.1$ & \multirow{2}{*}{0.81} & \multirow{2}{*}{$0.67-0.90$} & 0.02 & 0.1 \\
\hline & & 2 nd & $1.0 \pm 0.2$ & & & 0.03 & 0.1 & $0.9 \pm 0.1$ & & & 0.02 & 0.1 \\
\hline & \multirow[t]{2}{*}{ PMCT-ARA } & $1 \mathrm{st}$ & $0.9 \pm 0.2$ & \multirow{2}{*}{0.86} & \multirow{2}{*}{$0.75-0.93$} & 0.03 & 0.1 & $1.0 \pm 0.3$ & \multirow{2}{*}{0.91} & \multirow{2}{*}{$0.84-0.95$} & 0.04 & 0.1 \\
\hline & & 2 nd & $1.0 \pm 0.2$ & & & 0.03 & 0.1 & $1.0 \pm 0.2$ & & & 0.03 & 0.1 \\
\hline & PMCT-PRA & $1 \mathrm{st}$ & $1.1 \pm 0.2$ & & & 0.03 & 0.1 & $1.2 \pm 0.2$ & & & 0.03 & 0.1 \\
\hline & & 2 nd & $1.1 \pm 0.2$ & 0.11 & $0.61-0.88$ & 0.03 & 0.1 & $1.2 \pm 0.2$ & 0.80 & $0.64-0.89$ & 0.03 & 0.1 \\
\hline & IRD & $1 \mathrm{st}$ & $7.6 \pm 3.2$ & 099 & $098-099$ & 0.5 & 1.4 & & & & & \\
\hline & & 2 nd & $7.6 \pm 3.1$ & 0.39 & $0.90-0.93$ & 0.5 & 1.4 & & & & & \\
\hline & PMCT-EO & dayl & $1.4 \pm 0.4$ & & & 0.1 & 0.2 & $1.3 \pm 0.4$ & & & 0.1 & 0.2 \\
\hline & & day2 & $1.4 \pm 0.4$ & 0.93 & $0.80-0.90$ & 0.1 & 0.2 & $1.3 \pm 0.4$ & 0.93 & $0.80-0.90$ & 0.1 & 0.2 \\
\hline & PMCT-EO to IO & dayl & $0.9 \pm 0.2$ & 077 & $060-087$ & 0.03 & 0.1 & $1.0 \pm 0.2$ & 084 & $071-091$ & 0.04 & 0.1 \\
\hline & & day2 & $1.0 \pm 0.2$ & 0.11 & $0.00-0.01$ & 0.03 & 0.1 & $1.0 \pm 0.2$ & 0.07 & $0.11-0.91$ & 0.04 & 0.1 \\
\hline & PMCT-IO to TrA & dayl & $1.1 \pm 0.2$ & 077 & $061-087$ & 0.03 & 0.1 & $1.1 \pm 0.2$ & & $064-0,89$ & 0.03 & 0.1 \\
\hline & & day2 & $1.1 \pm 0.2$ & 0.11 & $0.61-0.8 /$ & 0.03 & 0.1 & $1.1 \pm 0.2$ & 0.19 & $0.64-0.89$ & 0.03 & 0.1 \\
\hline Between & PMCT-TrA & dayl & $1.0 \pm 0.2$ & 073 & $055-085$ & 0.03 & 0.1 & $0.9 \pm 0.1$ & 073 & $054-085$ & 0.02 & 0.1 \\
\hline Detwerie & & day2 & $1.0 \pm 0.1$ & 0.13 & $0.05-0.03$ & 0.02 & 0.1 & $1.0 \pm 0.1$ & 0.13 & $0.04-0.00$ & 0.02 & 0.1 \\
\hline & PMCT-ARA & day1 & $1.0 \pm 0.2$ & 072 & $053-084$ & 0.03 & 0.1 & $1.0 \pm 0.2$ & & $062-088$ & 0.03 & 0.1 \\
\hline & & day2 & $0.9 \pm 0.2$ & 0.12 & $0.53-0.84$ & 0.03 & 0.1 & $1.0 \pm 0.2$ & 0.18 & $0.62-0.88$ & 0.03 & 0.1 \\
\hline & PMCT-PRA & dayl & $1.1 \pm 0.1$ & 072 & $052-084$ & 0.02 & 0.1 & $1.2 \pm 0.2$ & 073 & $054-085$ & 0.03 & 0.1 \\
\hline & & day2 & $1.1 \pm 0.1$ & 0.12 & $0.02-0.04$ & 0.02 & 0.1 & $1.1 \pm 0.2$ & 0.13 & $0.04-0.03$ & 0.02 & 0.1 \\
\hline & IRD & day1 & $7.6 \pm 3.1$ & 0.98 & $097-099$ & 0.5 & 1.4 & & & & & \\
\hline & & day2 & $7.7 \pm 2.9$ & 0.70 & (נ) & 0.5 & 1.3 & & & & & \\
\hline
\end{tabular}

ICC: intraclass correlation coefficient; SEM: standard error of measurement; $95 \%$ CI: 95\% confidence interval; $\mathrm{MDC}_{95}$ : minimal detectable change95\%; PMCT: perimuscular connective tissue; PMCT-EO: PMCT-external oblique; PMCT-EO to IO: PMCT-external oblique to internal oblique; PMCT-IO to TrA: PMCT-internal oblique to transversus abdominis; PMCT-TrA: PMCT-transversus abdominis; PMCT-ARA: PMCT-anterior rectus abdominis; PMCT-PRA: PMCT-posterior rectus abdominis; IRD: interrecti distance.

\section{RESULTS}

Table 1 shows the results of the within-day and between-day PMCT measurements by ultrasound. The ICC for both within-day and between-day PMCT measurements by ultrasound were $0.7-0.9$. The $95 \%$ confidence interval ranged from 0.5-0.9. PMCT measurements ranged from $0.02-1.4 \mathrm{~mm}$. SEM was $0.02-0.1 \mathrm{~mm}$ in PMCT of the abdominal wall muscle and $0.5 \mathrm{~mm}$ in IRD. MDC95 was $0.1-0.3 \mathrm{~mm}$ in the abdominal wall muscle and $1.3-1.4 \mathrm{~mm}$ in IRD. The mean value of AAWCT was $2.33 \pm 1.53 \mathrm{~mm}$ and that of LAWCT was $3.01 \pm 0.43 \mathrm{~mm}$.

\section{DISCUSSION}

In our study, the reliability of PMCT measurement by ultrasound was obtained from ICC $0.7-0.9$, and it was possible to judge from "good reliability" to "excellent reliability" ${ }^{23)}$. Although few studies have confirmed the reliability of PMCT by ultrasound, Whittaker et al. performed ultrasound measurement of AAWCT of the front abdomen and PMCT of the side abdomen to compare a chronic low back pain group with a control group ${ }^{12}$. Among them, only IRD reports ICC, and intraexaminer ICC reported a high value of 0.99 both with-in day and between-day measurement. The PMCT measurement by ultrasound in our study was not as high as the ICC as reported in the study by Whittaker et al., but we verified it, except for IRD, and confirmed a certain reliability of ICC 0.7 to 0.9 . The values of measurement of the control group in the Whittaker 
et al. study reported AAWCT, LAWCT, and IRD and were $2.0 \mathrm{~mm}, 2.3 \mathrm{~mm}$, and $7.4 \mathrm{~mm}$, respectively. Similar to Whittaker's method, the results of our study were the same (except PMCT-EO). The results were $2.05 \mathrm{~mm}$ for AAWCT, $3.01 \mathrm{~mm}$ for LAWCT, and $7.6 \mathrm{~mm}$ for IRD. The LAWCT values were slightly larger, but almost no significant difference was observed. In a study by Morales et al. ${ }^{25)}$, PMCT was measured by ultrasound in amateur and elite athletes. Although no ICC was reported, the thickness of the left and right PMCTs of amateur athletes was reported to be $0.06-0.9 \mathrm{~cm}$ when compared to the measured values. The result of our research this time was $0.9-1.4 \mathrm{~mm}(0.09-0.14 \mathrm{~cm})$, and no significant difference was seen.

In this study, we conducted a study to confirm the reliability of PMCT measurement of abdominal wall muscle by ultrasound. From the results, a certain reliability was recognized. However, the method of measuring PMCT by ultrasound is not unified, and in this study, the method of determining the PMCT edge from the measured image was performed visually. From the obtained values, it was found that it contained a very small value of $0.02-1.4 \mathrm{~mm}$, so that it was difficult to perform visual measurement, and there was a limit in reliability. Future studies should consider methods of determining the PMCT edge that use computer software that measure echogenicity, as in the study by Langevin et al ${ }^{13)}$.

The limitations of the present study are that it was first only measured in healthy young adult males, and second, only an examination of the intra-rater reliability. In addition, there is a limit in that the PMCT edge is visually determined on the screen of the ultrasound device. Furthermore, the measurement area was also measured only by the abdominal wall PMCT. In the future, it is considered necessary to confirm whether reliability could be obtained for measurements on females and the elderly. It is also necessary to study whether the reliability of ultrasound measurements can be obtained with PMCT of other parts. Furthermore, it was considered necessary to study the significance of measuring PMCT by ultrasound by comparing males and females, and young and elderly.

\section{Conflict of interest}

There are no conflicts of interest to declare.

\section{REFERENCES}

1) Williams DA, Feuerstein M, Durbin D, et al.: Health care and indemnity costs across the natural history of disability in occupational low back pain. Spine, 1998, 23: 2329-2336. [Medline] [CrossRef]

2) Frymoyer JW: Back pain and sciatica. N Engl J Med, 1988, 318: 291-300. [Medline] [CrossRef]

3) Deyo RA, Weinstein JN: Low back pain. N Engl J Med, 2001, 344: 363-370. [Medline] [CrossRef]

4) Hodges PW, Richardson CA: Inefficient muscular stabilization of the lumbar spine associated with low back pain. A motor control evaluation of transversus abdominis. Spine, 1996, 21: 2640-2650. [Medline] [CrossRef]

5) Hodges PW, Richardson CA: Delayed postural contraction of transversus abdominis in low back pain associated with movement of the lower limb. J Spinal Disord, 1998, 11: 46-56. [Medline] [CrossRef]

6) Grimstone SK, Hodges PW: Impaired postural compensation for respiration in people with recurrent low back pain. Exp Brain Res, 2003, 151: 218-224. [Medline] [CrossRef]

7) Roland MO: A critical review of the evidence for a pain-spasm-pain cycle in spinal disorders. Clin Biomech (Bristol, Avon), 1986, 1: 102-109. [Medline] [CrossRef]

8) Macedo LG, Maher CG, Latimer J, et al.: Motor control exercise for persistent, nonspecific low back pain: a systematic review. Phys Ther, 2009, 89: 9-25. [Medline] [CrossRef]

9) Saragiotto BT, Maher CG, Yamato TP, et al.: Motor control exercise for nonspecific low back pain: a Cochrane review. Spine, 2016, 41: 1284-1295. [Medline] [CrossRef]

10) Ferreira ML, Ferreira PH, Latimer J, et al.: Comparison of general exercise, motor control exercise and spinal manipulative therapy for chronic low back pain: A randomized trial. Pain, 2007, 131: 31-37. [Medline] [CrossRef]

11) Park KN, Kwon OY, Yi CH, et al.: Effects of motor control exercise vs muscle stretching exercise on reducing compensatory lumbopelvic motions and low back pain: A randomized trial. J Manipulative Physiol Ther, 2016, 39: 576-585. [Medline] [CrossRef]

12) Whittaker JL, Warner MB, Stokes M: Comparison of the sonographic features of the abdominal wall muscles and connective tissues in individuals with and without lumbopelvic pain. J Orthop Sports Phys Ther, 2013, 43: 11-19. [Medline] [CrossRef]

13) Langevin HM, Stevens-Tuttle D, Fox JR, et al.: Ultrasound evidence of altered lumbar connective tissue structure in human subjects with chronic low back pain. BMC Musculoskelet Disord, 2009, 10: 151. [Medline] [CrossRef]

14) Stokes M, Hides J, Elliott J, et al.: Rehabilitative ultrasound imaging of the posterior paraspinal muscles. J Orthop Sports Phys Ther, 2007, 37: 581-595. [Medline] [CrossRef]

15) Teyhen DS, Gill NW, Whittaker JL, et al.: Rehabilitative ultrasound imaging of the abdominal muscles. J Orthop Sports Phys Ther, 2007, 37: 450-466. [Medline] [CrossRef]

16) Hides JA, Stanton WR, McMahon S, et al.: Effect of stabilization training on multifidus muscle cross-sectional area among young elite cricketers with low back pain. J Orthop Sports Phys Ther, 2008, 38: 101-108. [Medline] [CrossRef]

17) Koppenhaver SL, Hebert JJ, Fritz JM, et al.: Reliability of rehabilitative ultrasound imaging of the transversus abdominis and lumbar multifidus muscles. Arch Phys Med Rehabil, 2009, 90: 87-94. [Medline] [CrossRef]

18) Gnat R, Saulicz E, Miądowicz B: Reliability of real-time ultrasound measurement of transversus abdominis thickness in healthy trained subjects. Eur Spine J, 2012, 21: 1508-1515. [Medline] [CrossRef] 
19) Wilson A, Hides JA, Blizzard L, et al.: Measuring ultrasound images of abdominal and lumbar multifidus muscles in older adults: a reliability study. Man Ther, 2016, 23: 114-119. [Medline] [CrossRef]

20) Cuellar WA, Blizzard L, Callisaya ML, et al.: Test-retest reliability of measurements of abdominal and multifidus muscles using ultrasound imaging in adults aged 50-79 years. Musculoskelet Sci Pract, 2017, 28: 79-84. [Medline] [CrossRef]

21) Nanikawa W, Miyazaki J: Examination of the intrarater reliability of ultrasound measurements of the thickness of the lumbar and lateral abdominal muscles in the prone position. J Phys Ther Sci, 2019, 31: 645-648. [Medline] [CrossRef]

22) Murakami T, Sakuraba K, Nagai K: Comparison of changes in the transversus abdominis and neighboring fascia in subjects with and without a history of low back pain using ultrasound imaging. J Phys Ther Sci, 2011, 23: 317-322. [CrossRef]

23) Cicchetti DV, Sparrow SA: Developing criteria for establishing interrater reliability of specific items: applications to assessment of adaptive behavior. Am J Ment Defic, 1981, 86: 127-137. [Medline]

24) Weir JP: Quantifying test-retest reliability using the intraclass correlation coefficient and the SEM. J Strength Cond Res, 2005, 19: 231-240. [Medline]

25) Morales CR, Polo JA, Sanz DR, et al.: Ultrasonography features of abdominal perimuscular connective tissue in elite and amateur basketball players: an observational study. Rev Assoc Med Bras (1992), 2018, 64: 936-941. [Medline] [CrossRef] 